\title{
The Legal Battle With THE FUtURe OF Autonomous Surgical Robotics
}

\author{
ANDREW VILLANUEVA
}

\section{INTRODUCTION}

In a world where technology has never stood still, nor stopped developing, the law has always been in the rearview mirror. ${ }^{1}$ Thus, resulting in a strong need to develop, regulate, and enforce laws, statutes, and regulatory bills that are associated with advanced technology. ${ }^{2}$ With rapid advancements of artificial intelligence and autonomous robotics within the private lives of citizens and the public sectors of companies, the realm of law is in need of solutions of how to handle the legal repercussions of such a rapid succession of technological change. ${ }^{3}$ The advancement from partial autonomous robotics into the futuristic notion of fully autonomous surgical robotics will create new areas of legal problems and concerns that should be addressed before they arise. ${ }^{4}$ This need for a preemptive solution is based on the risk of health and lives associated with the medical practice and the whole realm of medicine. ${ }^{5}$

It remains to be seen whether robotic systems will be regulated and how they will be handled within the legal system. ${ }^{6}$ Ronald Lees and his fellow researchers determined that there are four factors that need to be considered when addressing any and/or all future legal issues arising out of advanced surgical robotics: "law, market, social norms, and technology." Each presenting a key consideration that should contribute to the formulation of relevant statutes or legal precedents. ${ }^{8}$ In any case, with or without proper regulations and statutory law, robotic technology has already begun to revolutionize surgery by improving, expanding, and developing procedures, by advancing surgical technology and bringing surgery into the digital age. ${ }^{9}$ As the future continues to draw near, the reality of further ability of semi-autonomous robotics being present in our society and

1. See Daniel Malan, The law can't keep up with new tech. Here's how to close the gap, WORLD ECON. F. (June 21, 2018), https://www.weforum.org/agenda/2018/06/law-too-slow-fornew-tech-how-keep-up/ [https://perma.cc/93SF-SSXT].

2. See id.

3. See Ronald Leenes et al., Regulatory Challenges of Robotics: Some Guidelines for Addressing Legal and Ethical Issues, 9 L. InNOVATION \& TeCH. 1, 7 (2017).

4. See David Britton, Automating Surgery: The Law of Autonomous Surgical Robots, J.L. \&TECH. TEXAS. (2016).

5. See Paul Cerrato, Medical Device Security: Is Your Facility at Risk?, MEDPAGE TODAY, https://www.medpagetoday.com/resource-centers/osteoporosis/medical-device-security-yourfacility-risk/693[https://perma.cc/AZG2-TKVQ].

6. See Leenes, supra note 3 , at 7.

7. Id. at 1 .

8. See id.

9. See New surgical robots are about to enter the operating theatre, ECONOMIST (Nov. 16, 2017), https://www.economist.com/science-and-technology/2017/11/16/new-surgical-robots-areabout-to-enter-the-operating-theatre [https://perma.cc/R4NY-SG5J]. 
medical realm becomes less of a dream and more of a reality. ${ }^{10}$ Yet again, reflecting the need for our legal system to create strong regulatory standards for current and future surgical robotics. ${ }^{11}$ Though surgical robotics maintain the potential to expand surgical treatments and medical practices beyond the limits of human ability, while reducing human error, there still remain the worst-case situations. ${ }^{12}$ Situations involving systematic robotic failure, resulting in serious bodily injury or even death and thus creating the legal issue of what parties should be held liable in relation to the systematic failure. ${ }^{13}$ A clear example of this is demonstrated by Laurie Featherstone who put all her faith in the doctor and didn't ask questions when her colon and ureter were damaged during a robotic surgery. ${ }^{14}$

This article critically examines the concepts, possibilities, problems, and possible legal solutions that will occur when the use of fully autonomous surgical robotics become part of everyday practice within the medical field. ${ }^{15}$ As fully autonomous surgical robotics become a real possibility, a solution based on historic precedent and statutes must be considered when formulating a future solution to deal with legal issues involving fully autonomous surgical robotics. In order to create such a solution, an explanation and breakdown of the fundamentals and concepts of what robotics are and how they function in the realm of modern medicine is required. Secondly, by analyzing the historic foundation of current semi-autonomic robotics' statutes and case law that is being used in today's current medical society to better understand what is required in the future. Lastly, through an analogy of automotive and aviation, an in-depth analysis of how the current legal system is handling fully autonomous robotics and how to create solutions for both current and future legal issues associated that would best fit the needs for both current and future society. Overall, by expanding and analyzing all the information as stated above, a potential foundational solution can be generated to help regulate and handle future legal disputes arising

10. Eliza Strickland, Autonomous Robot Surgeon Bests Humans in World First, IEEE SPECTRUM (May 4, 2016, 6:17 PM), https://spectrum.iee.org/the-human-os/robotics/medicalrobots/autonomous-robot-surgeon-bests-human-surgeons-in-world-first [https://perma.cc/CKB3$\mathrm{ZPXH]}$.

11. See Leenes, supra note 3 , at 1,7 .

12. See Jeremy Russell, The Future of Medical Robotics, IT ProPorTal (Nov. 24, 2017), https:/www.itproportal.com/features/the-future-of-medical-robotics/ [https://perma.cc/W6SFCS99].

13. See Markus Christen et al., An Evaluation Schema for the Ethical Use of Autonomous Robotic Systems in Security Applications, 1, 55-56 (2017), https://philarchive. org/archive/CHRAES-3 [https://perma.cc/5HKL-FHMC].

14. Emily Siegel et al., The da Vinci Surgical Robot: A Medical Breakthrough with Risks for Patients, NBC News (Dec. 19, 2018, 6:29 PM), https://www.nbcnews.com/health/health-news/davinci-surgical-robot-medical-breakthrough-risks-patients-n949341 [https://perma.cc/ESW5-M2FS].

15. See generally How are Robots Changing Healthcare, HealthCare Admin. Degree PROGRAMS, https://www.healthcare-administration-degree.net/faq/how-are-robots-changinghealthcare/ [https://perma.cc/V8CV-9DCQ]. 
out of the usage and failure of fully autonomous surgical robotics.

\section{BACKGROUND}

\section{A. Basic Concepts of Robotics}

Today, robots are generally understood to be machines that are programmed by computers, which allows them to be capable of completing a series of actions automatically. ${ }^{16}$ Furthermore, these robotics contain additional abilities to process data or physical perceptions electronically, operate, move, operate physical parts of, sense and manipulate their environment, and exhibit intelligent behavior, especially behavior which mimics humans or other animals. ${ }^{17}$ These abilities allow robotics to be able to participate in common human interactions, such as, "playing chess ... recognizing faces and driving safely." robotics in today's world impact almost every single person's life in some manner. ${ }^{19}$ A classic example of this can be seen within the world of telephone communication, "[w]e have gone from simple LAN phones to super-smart cell phones that are taking over the realm of the laptop." ${ }^{20}$ More specifically, advancements in the realm of robotics have allowed them to become key centerpieces in medical procedures. ${ }^{21}$ This ability is exemplified by robots containing "characteristic features include the capability to move along multiple axes (directions), programmability, and a closed sensory loop allowing the machine to react to sensory input." ${ }^{\prime 2}$ These characteristic features have allowed doctors, surgeons, and other medical professionals to perform more precise, quicker, and less intrusive surgeries over the years. ${ }^{23}$ As stated by Dr. Bertalan Mesko, $\mathrm{PhD}$, founder of the Medical Futurist, the usage of current and future robotics "will help to make healthcare sustainable and much more efficient in the future." ${ }^{4}$ According to a study performed in 2004, "[t]oday robots are used to perform highly specific, highly precise, and dangerous tasks in industry and

16. See Robot, Oxford English Dictionary (2d ed. 2017).

17. See Tom Harris, How Robots Work, HowStufFWorks (April 16, 2002), https://science. howstuffworks.com/robot.htm [https://perma.cc/MZG8-XNP6].

18. George Musser, What the Rise of Sentient Robots Will Mean for Human Beings, NBC NEws: MACH (June 19, 2017, 1:15 PM), https://www.nbcnews.com/mach/tech/what-rise-sentientrobots-will-mean-human-beings-ncna773146 [https://perma.cc/4KHX-S9QU].

19. See id.

20. See Len Calderone, Advancement of Robots in Medicine, Roвotics Tomorrow (May 15, 2018, 8:24 AM), https://www.roboticstomorrow.com/article/2018/05/advancement-of-robots-inmedicine/11948 [https://perma.cc/UP47-79HZ].

21. See Russell, supra note 12.

22. Expert Report and Affidavit, Fuji Am. Corp. v. U. S., No. 03-00126, 2003 WL 2510697.

23. See Russell, supra note 12.

24. Id. 
research previously not possible with a human workforce." ${ }^{25}$ Specifically, the stated abilities and features above will be key concepts and notions that will arise from the future capabilities of autonomous surgical robotics. ${ }^{26}$

\section{B. Autonomous Robotics}

In order to understand the importance and issues that occur with autonomous surgical robotics, it is key to understand the basic fundamentals of what autonomous surgical robotics are and how they operate. Webster Dictionary defines autonomy as "with reference to a thing: the fact or quality of being unrelated to anything else, self-contentedness; independence from external influence or control, self-sufficiency." 27 Furthermore, District of Colombia legislators have expanded and legally defined autonomy, in terms of vehicles, to be "a vehicle capable of navigating District roadways and interpreting trafficcontrol devices without a driver actively operating any of the vehicle's control systems." 28 Though basic in definition, it still demonstrates both current and futuristic possibilities of autonomous technology can produce not only in the realm of medicine but in society as a whole.

As society has progressed, the concepts and abilities surrounding autonomous robotics have too. ${ }^{29}$ As stated earlier, the main focus of this note is centered around the futuristic possibility of fully autonomous robotics being part of the medical realm. This notion of fully autonomous robotics may seem far-fetched in theory, but it is a very realistic notion.$^{30}$ Researchers have opined: "[m]uch like the robots in popular culture, the future of robotics in surgery is limited only by imagination. Many future 'advancements' are already being researched." ${ }^{31}$ These advancements in technology have already and will continue to change how industries function. As emphasized, advanced robotics not only allow the practice of medical procedures to be safer, the advancement of robotics will allow companies and industries as a whole to become more productive and hopefully create a strong sector in the economy. ${ }^{32} \mathrm{~A}$ clear example of this advancement can be seen through the withdrawal of blood for blood sample tests. Robotics maintain the capabilities to determine which veins are "good veins," instead of having a medical professional insert numerous needles in order to determine

25. See Anthony R. Lanfranco, Andres E. Castelllanos, Jay P. Desai \& William C. Meyers, Robotic Surgery: A Current Perspective, 239 ANN. SuRgERY 14, 18, 19 (2004).

26. See Russell, supra note 12.

27. Autonomy, OXford English Dictionary (2nd ed. 2017).

28. D.C. CODE $§ 50-2351(1)(2013)$.

29. See Robotics in Healthcare -- Get Ready!, MED. FutURIST (2016), https://medicalfuturist. com/robotics-healthcare [https://perma.cc/A2EA-XKAT].

30. Id.

31. Lanfranco, supra note 25 , at 20.

32. Scott A. Wolla, Will Robots Take Our Jobs?, ECON. Res. Fed. Res, BANK St. Louis (Jan. 2018), https://research.stlouisfed.org/publications/page1-econ/2018/01/02/will-robots-take-our-jobs [https://perma.cc/MML8-G4GX]. 

AUTONOMOUS SURGICAL ROBOTICS

which vein is best for the procedure..$^{33}$ Additionally, a test between a human doctor and autonomous robotics provides vital insight and demonstrates that this notion of fully autonomous surgical robotics is a realistic possibility as technology and society progress. ${ }^{34}$ The test was centered and focused on "a bot stitched up a pig's small intestines using its own vision, tools, and intelligence to carry out the procedure ... [w]hat's more, the Smart Tissue Autonomous Robot (STAR) did a better job on the operation than human surgeons who were given the same task." 35 This revolutionary breakthrough portrays a clear indication that the notion of the fully autonomous robotics is not some concept only seen in movies such as "Star Wars" but rather is a concept that is going to be a key and common foundation within the realm of medical procedures. From determining best veins for blood samples to stitching up intestines, these breakthroughs demonstrate that fully autonomous robotics are coming now. Rather, instead of waiting for issues to arise later, it would be best to create a legal solution now in anticipation of future issues. Further, a more commonly known medical procedure, telesurgery, provides even more foundational support. Telesurgery in its basic understanding can be described as "[a]nother avenue of growth in the field of robotic surgery ... where the surgeon is not in the same location or even in the vicinity of the patient being operated on." ${ }^{36}$ Though telesurgery is different from autonomous robotic surgery, the notion that telesurgery is developing is a great indication that the overall concept of autonomous robotics surgery is not as far-fetched as some may believe. The commonly asked question when one is either reading or hearing about said surgical robotics, is how does it work? As stated above, one of the most common ways one of the most common ways the current medical community is through telesurgery. In its most basic form/description, the surgical robot is controlled by "a nearby console, [with which the] surgeon manipulates those instruments to perform the operation." ${ }^{\prime 37}$ Some have considered it to be like playing a real-life video game. ${ }^{38}$ The "surgeon is in control the whole time; the surgical system responds to the direction he provides." ${ }^{\prime 3}$ Not only through studies are fully autonomous robotics proven to be a realistic notion, but this notion is also supported through the use of partial and fully autonomous robotics in today's modern vehicles. ${ }^{40}$ The notion of self-

33. See How are Robots Changing Healthcare, supra note 15.

34. See Strickland, supra note 10.

35. Id.

36. Jay Shah, Arpita Vyas \& Dinesh Vyas, The History of Robotics in Surgical Specialties, 12 Am. J. Robotic Surgery 11 (2014).

37. About Robotic Surgery at UCLA, UCLA HEALTH, https://www.uclahealth.org/roboticsurgery/what-is-robotic-surgery [https://perma.cc/JN4S-73FP].

38. See Klint Finley, How Videogames Could Help Train the Next Generation of Robotic Surgeons, WIRED: SCI., https://www.wired.com/2012/12/robotic-surgery-and-gaming/ [https:// perma.cc/TB56-9T7Q].

39. $I d$.

40. See, Kersten Hineke et al., Self-Driving Car Technology: When Will the Robots Hit the 
driving cars is a clear indicator that the technology for fully autonomous robotics is already out in society and is developing at a rapid rate. Pediatric surgeon Peter Kim expanded on this connection/correlation by stating " "[n]ow driverless cars are coming into our lives ... [i]t started with self-parking, then a technology that tells you not to go into the wrong lane. Soon you have a car that can drive by itself. Similarly, he said, 'surgical robots could start by giving human surgeons a helping hand. And maybe one day they'll take over."'41

As stated above, it can be very clearly concluded that this is not a moot point. The notion of fully autonomous robotics is a point that is one already in our society, ${ }^{42}$ and a too realistic notion that is coming fast for the realm of medicine. ${ }^{43}$ The realm of law slow-moving in nature, detail-driven, and results in the common perception that cases generally take too long to enter and make their way through American courts. ${ }^{44}$ The notion of fully autonomous surgical robotics is a concept that should be addressed before the problems occur as both money and lives are at risk within the realm of medicine and society.

\section{USAGE AND DEVELOPMENT OF SURGICAL ROBOTICS}

Since the FDA approved the use of robotics within medical procedures and surgeries, there has been rapid growth to make said robotics more effective, quicker, and overall a better plan. ${ }^{45}$ Furthermore, since the approval of the da Vinci-assisted surgical robot and other similar counterparts, there has been "a total of 1.745 million robotic surgeries . . . between the years 2000-2013 in the USA. ${ }^{46}$ This large number alone can reflect how ingrained surgical robotics are in everyday use within the modern realm of medical practices. ${ }^{47}$ As stated by Sanja Dogramadzi, a professor in medical robotics at the University of the West

Road?, McKinsey \& COMPANY: OUR InSIGHT (May 2017), https://www.mckinsey.com/industries/ automotive-and-assembly/our-insights/self-driving-car-technology-when-will-the-robots-hit-theroad [https://perma.cc/6NZF-9D3F].

41. Strickland, supra note 10.

42. See Nabeel Hyatt, Autonomous Driving is Here, and It's Going to Change Everything, RECODE (Apr. 19, 2017, 7:30 PM), https:/www.recode.net/2017/4/19/15364608/autonomous-selfdriving-cars-impact-disruption-society-mobility [https://perma.cc/EJX5-SC49].

43. See Harold Stark, Prepare Yourselves, Robots Will Soon Replace Doctors in Healthcare, FORBES (Jul. 10, 2017 1:00 PM), https:/www.forbes.com/sites/haroldstark/2017/07/10/prepareyourselves-robots-will-soon-replace-doctors-in-healthcare/ [https://perma.cc/P3JZ-ENSL].

44. Mary Lee Luskin \& Robert C. Luskin, Why So Fast, Why So Slow: Explaining Case Processing Time, 77 J. CRIM. L, \& CRIMINOLOGY 190, 190 (1986).

45. See generally Alessia Ferrarese, et al., Malfunctions of Robotic System in Surgery: Role and Responsibility of Surgeon in Legal Point of View, 11 OpEn MED. 286, 286 (2016).

46. Fatih Hitami Usluoğulları, Sitkı Tiplamaz, \& Nesime Yayci, Robotic Surgery and Malpractice, 43 TURKish J. UROLOGY 425, 425 (2017).

47. See Jo Best, Robots and the NHS: How Automation Will Change Surgery and Patient Care, ZD NET (Nov. 19, 2018), https://www.zdnet.com/article/robots-and-the-nhs-how-automationwill-change-surgery-and-patient-care/ [https://perma.cc/X3ZT-Z5MK]. 
of England's Bristol Robotics Laboratory, "in the years to come we will see subsystems gaining more autonomy in order to allow the surgeon to do things faster, better, and more precisely." ${ }^{18}$ At this very moment, there are considered to be eleven "big brands": da Vinci, Sensei X Robotic, CorPath 200, Vdrive robotic, Rosa Brain, Rosa Spine, Senhance, Titan Sport robot-assisted surgery platform, Mako Rio robot, Smith \& Nephew's Navio surgical system, Medrobotics' Flex Robotic System, and Mazor Robotics Renaissance Guidance System. ${ }^{49}$ Just as in the automotive industry, each brand has its own 'signature mark,' "special features," and skills for specific tasks or objectives than its competitors. ${ }^{50}$ The Da Vinci robots were used in over "600,000 surgeries in 2016 and the system is capable of aiding surgeons with everything from hysterectomies to prostatectomies.

However, just like humans, robots are not perfect. Even surgical robotics have failed and continue to do so. ${ }^{51}$ These failures have been proven to be caused by two factors, one being the surgeons' inability to use the device properly, and two being device dysfunction. ${ }^{52}$ Device dysfunction varies and is dependent on what brand's device is used and what surgical performance is being rendered by the device. ${ }^{53}$ A specific example can be seen within the Sensei X Robotic, which became "loose relative to the operating table with the potential for the device to fall causing, uncontrolled catheter movement. The cardiac tamponade, delayed procedure, or crush [can cause] injury to the patient and/or user." ${ }^{, 54}$ In order to determine how frequently these errors occur, a study was performed from 20042015 that produced a result that showed that of the "386 malfunctions were described out of 14141 procedures, $20.9 \%$ of which was damage caused by malfunction of the [Robotic Surgery]RS arms and instruments." 55 An additional study from 2003 to 2013 produced the results that 144 deaths $(1.4 \%$ of the 10,624 reports), 1,391 patient injuries (13.1\%), and 8,061 device malfunctions (75.9\%). ${ }^{56}$ Furthermore, by 2015 there have already been "144 deaths and more than 1,000

48. Id.

49. Fink Densford, 11 Surgical Robotics Companies You Need to Know, Mass DeviCE (Feb. 1, 2017), https://www.massdevice.com/11-surgical-robotics-companies-you-need-to-know/ [https:// perma.cc/F2R3-J6VY].

50. See Mathias Hoeckelmann et al., Current Capabilities and Development Potential in Surgical Robotics, 12 InT'L J. AdVANCED Robotic Sys. (Jan. 1, 2015).

51. See Homa Alemzadeh et al., Adverse Events in Robotic Surgery: A Retrospective Study of 14 Years of FDA Data, 11 Plos OnE 4 (2016).

52. Ferrarese, supra note 45, at 286.

53. Id. at 288 .

54. Michelle Bayefsky \& Benjamin E. Berkman, FDA's Proposed Guidance for Laboratory Developed Tests: How Should Regulators Balance the Risks and Promise of Innovation in Clinical Genetics?, 5 FDLI's FOOD \& DRUG POL'Y F. (2015).

55. Ferrarese, supra note 45, at 287.

56. Alemzadeh, supra note 51, at 4. 
injuries" linked directly to the usage of surgical robotics. ${ }^{57}$ Though on the face, these numbers seem large and extreme, they are smaller compared to the deaths and injuries that occur worldwide due to the human error rates within surgical procedures..$^{58}$ Thus, it makes the application of surgical robotics more appealing as the technology advances and error rates drop..$^{59}$ As many professionals have confirmed and/or stated, "the lurking fear of legal action and even just the desirable reassurance of having an expert on hand for those awful "what-ifs." As stated above and continuing below, those "what-ifs" can turn into messy, long, and costly litigation if no proper case law or statute is presented in order to help the court system be guided through the challenges of disputes of technology.

\section{SOCIETY USAGE OF AUTOMATIC RoBOTICS}

The usage and notion of autonomous robotics have been historically related to the automotive industry, ${ }^{61}$ and less frequently thought the aviation industry. As stated earlier, this note is focusing its argument through an analogy of how states and the nation as a whole have handled other industries in relation to their usage of automatic robotics. Congress stated in 2016, that self-driving vehicles reduce the notion of crashes produced by alcohol consumption and driving, and over

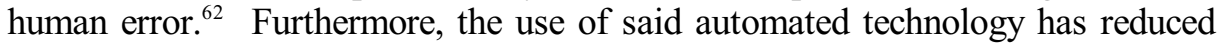
the dependency/need for skilled pilots, with high rated capabilities.$^{63}$ Again, stressing the overarching issue of increasing societal safety, the implementation of autonomous robotics.

Automatic robotics within the automotive industries are commonly known as self-driving cars ${ }^{64}$ The strong societal push for the use of autonomous robotic vehicles is due to the notion of human error and it's relation to crashes and other similar issues of human driving-related injuries. ${ }^{65}$ These issues can be proven by

57. Robotic surgery linked to 144 deaths in the US, BBC News (July 22, 2015), https://www.bbc.com/news/technology-33609495 [https://perma.cc/KW76-MQ2M].

58. Id.

59. See id.

60. Mark Piesing, Medical robotics: Would you trust a robot with a scalpel?, GUARDIAN (Oct. 10, 2014, 4:00 PM), https://www.theguardian.com/technology/2014/oct/10/medical-robotssurgery-trust-future [https://perma.cc/MA8G-KL3H].

61. See WIRED Brand Lab for Ford Motor Company, A Brief History of Autonomous Vehicle Technology, WIRED, https://www.wired.com/brandlab/2016/03/a-brief-history-of-autonomousvehicle-technology/ [https://perma.cc/4YDY-VVWV] .

62. Hands Off: The Future of Self-Driving Cars: Hearing Before the S. Comm. on Commerce, Sci, and Transp., 114th Cong. (2016).

63. Id.

64. See David Benady, Self-driving Cars to Hospital Robots: Automation Will Change Life and Work, GuARDiAn (Mar. 30, 2016), https://www.theguardian.com/sustainable-business/2016/ mar/30/robot-economy-workforce-artificial-intelligence [https://perma.cc/77TH-KQS3].

65. See U.S. Dep't of Transp. \& Nat'L Highway Traffic Safety Admin., Automated DrIVING SyStems 2.0, A VISION FOR SAFETY 2 (2017), https://www.nhtsa.gov/sites/nhtsa. 
"[t]he major factor in 94 percent of all fatal crashes is human error . . ADSs [Automatic Driving Systems] have the potential to significantly reduce highway fatalities by addressing the root cause of these tragic crashes." ${ }^{\circ 6}$ One of the most vivid examples that come to one's mind is Google's self-driving car. ${ }^{67}$ This classic example is completely automatic due to the car having complete control over the gas, brake, and steering systems. ${ }^{68}$ Additionally, Uber and Telsa maintain their own line of self-driving automotive vehicles.$^{69}$ Uber's autonomous vehicle is officially known as "Otto", which is equipped with radar, cameras, lidar, and other automated technology. ${ }^{70}$ This would allow a truck driver to sleep while the truck is driving itself. ${ }^{71}$ As for Telsa, their autonomous automotive line consists of models $\mathrm{X}$ and $\mathrm{S}$, which contain "hardware - cameras, ultrasonic sensors, and an onboard supercomputer-for self-driving", and additionally contains a chip known as NVIDIA that gives the car "eyes" to analyze and interpret its surroundings in order to make the logically correct driving decisions. ${ }^{72}$ Though these examples are similar in nature, the difference that makes each brand of vehicle autonomous is a factor that lawmakers and the court systems may and must take into consideration when trying to determine the appropriate action. This can be directly related back to the eleven big brands that are maintained and produced within the medical realm. This may end up being a key factor and influencer when creating future laws and statutes centering fully autonomous surgical robotics. ${ }^{73}$ Meaning, if the national government and or states implement laws that handle each brand of autonomous vehicle differently, one could predict a very similar implementation of laws towards the brands that control the autonomous surgical robotic industry. Though fully autonomous surgical robotics may not be on the market for the medical realm, the technology for such robotics is currently being used within society as we speak. Thus, making autonomous surgical robotics a very real notion that should gain the respect of the legal system. Lawmakers will be faced with these issues surrounding the advanced surgical robotics within our near future.

dot.gov/files/documents/13069a-ads2.0_090617_v9a_tag.pdf [https://perma.cc/2YUT-QYNJ].

66. Id.

67. See Samuel Gibbs, Google's self-driving car: How does it work and when can we drive one?, GUARDIAN (May 29, 2014), https://www.theguardian.com/technology/2014/may/28/googleself-driving-car-how-does-it-work [https://perma.cc/8ALA-X65H].

68. Id.

69. John Markoff, Want to Buy a Self-Driving Car? Big-Rig Trucks May Come First, N.Y. Times (May 17, 2016), https://www.nytimes.com/2016/05/17/technology/want-to-buy-a-selfdriving-car-trucks-may-come-first.html [https://perma.cc/V59F-U978].

70. See id.

71. Id.

72. See Jack Stewart, Tesla Says Its New Self-Driving Chip Is Finally Baked, WIRED (Aug. 4, 2018), https://www.wired.com/story/tesla-self-driving-car-computer-chip-nvidia/ [https://perma. cc/2ANL-XN6Z].

73. See generally Densford, supra note 49. 


\section{STATUES AND REGULATIONS}

\section{A. Automotive Statues and Regulations}

\section{Federal Statutes and Regulations}

As examined above, the rapid development of autonomous robotics within both the automotive and aviation industries have produced and contributed great benefits in today's society. However, though these technological advancements have produced benefits, there are still issues on how to regulate said technology and how to handle cases within a court of law when an autonomous robotics system fails. ${ }^{74}$ States and the nation as a whole are struggling to define notions and concepts such as, "vehicle operator," "autonomous driving system," and whether or not the vehicle must contain safe features consisting of "human operator." All of which are terms and concepts that would be key in any legal dispute, settlement, or statute moving forward. Below are a discussion and indepth analysis of a major national and state regulatory standard that was developed to determine key features to help regulate autonomous surgical robotics in the future.

Both on a federal and state level, lawmakers have taken action to pass legislation in order to classify and regulate autonomous vehicles that may enter the public streets. ${ }^{75}$ The best illustration of how states have handled the development of autonomous robotics is seen within Michigan and Colorado legislation. ${ }^{76}$ In addition to federal bills and states' bills, the U.S. Department of Transportation (DOT), through the National Highway Traffic Safety Administration (NHTSA), is taking a large stronghold in regulating autonomous robotic vehicles. ${ }^{77}$ Specifically, the NHTSA has created "[t]he Voluntary Guidance contain[ing] 12 priority safety design elements." there are clear recommendations and guidelines that all autonomous vehicles should maintain or have the ability to perform. However, as the title of the guide states, these are voluntary elements and not required by law. Though they are not forced to follow the guidance elements for autonomous vehicles, the principle of each element could be something that could be used when developing the possible solution for fully autonomous surgical robotics. Through studies and

74. See Darrell M. West \& John R. Allen, How Artificial Intelligence is Transforming the World, BROOKINGS (Apr. 24, 2018), https://www.brookings.edu/research/how-artificialintelligence-is-transforming-the-world/ [https://perma.cc/BD49-2GZQ].

75. See Autonomous Vehicles | Self-Driving Vehicles Enacted Legislation, NAT'L Conf. StATE Legislatures (Oct. 9, 2019), http://www.ncsl.org/research/transportation/autonomousvehicles-self-driving-vehicles-enacted-legislation.aspx [https://perma.cc/59C3-HE39].

76. $I d$.

77. See generallyU.S.DeP'T of TransP. \& NAT'L Highway Traffic SAFEty Admin., supra note 65 .

78. Id. at 1. 
research, the 12-element safety design is meant to help, support, and "reach[]an era of crash-free roadways through the deployment of innovative lifesaving technologies." ${ }^{\text {79 }}$

"Element 1: System Safety," ${ }^{80}$ focuses on encouraging entities to "follow a robust design and validation process based on a systems-engineering approach with the goal of designing ADSs free of unreasonable safety risks. The overall process should adopt . . . the functional safety process standard for road vehicles, and collectively cover the entire operational design domain . . of the system."

"Element 2: Operational Design Domain," ${ }^{82}$ focuses on the capabilities of the vehicle on roadway types (interstate, local, etc.), geographic area (city, mountain, desert, etc.), safety operation features, speed range, and environmental conditions in which the ADS will operate (weather, daytime/nighttime, etc.). ${ }^{83}$

"Element 3: Object and Event Detection and Response," $"{ }^{84}$ analyzes the capabilities and functions of "the ability to address a wide variety of foreseeable encounters, including emergency vehicles, temporary work zones, and other unusual conditions (e.g., police manually directing traffic or other first responders or construction workers controlling traffic) that may impact the safe operation of an ADS." ${ }^{\circ 5}$

"Element 4: Fallback (Minimal Risk Condition)," ${ }^{\prime 66}$ creates a foundation for basic requirements in case of robotic failures. "[E]ntities are encouraged to have a documented process for transitioning to a minimal risk condition" when the robotic systems fail and there need for human driver intervention. ${ }^{87}$

"Element 5: Validation Methods," research in order to develop the best and safest autonomous robotic technology for market use. Manufacturers should continue to develop tests and "entities are encouraged to develop validation methods to appropriately mitigate the safety risks associated with their ADS approach." 89

"Element 6: Human Machine Interface," $" 90$ entities are encouraged to broadcast, develop and explain how the human and machine relationship works within the systematic use of the vehicle and should make:

Considerations should be made for the human driver, operator,

79. Id.

80. Id. at 5 .

81. Id.

82. Id. at 6 .

83. Id.

84. Id at 7 .

85. Id.

86. Id. at 8 .

87. Id.

88. Id. at 9

89. Id.

90. Id. at 10 . 
occupant(s), and external actors with whom the ADS may have interactions, including other vehicles (both traditional and those with ADSs), motorcyclists, bicyclists, and pedestrians. HMI design should also consider the need to communicate information regarding the ADS's state of operation relevant to the various interactions it may encounter and how this information should be communicated. ${ }^{91}$

Furthermore, unlike the rest of the elements where the NHTSA encourages or promotes the bare minimum standards, in order to fulfill the standard behind Element 6: Human Machine Interface, "[a]n ADS should be capable of informing the human operator or occupant through various indicators that the ADS are: [f] unctioning properly, [e]xperiencing a malfunction, and/or [c]urrently engaged in ADS mode, [r] equesting control transition from the ADS to the operator, and [c]urrently "unavailable" for use." ${ }^{92}$ Thus, making Element 6 a key element to consider when lawmakers are creating a future solution in relation to autonomous surgical robotics.

"Element 7: Vehicle Cybersecurity," 93 reflects an overarching industry standard that should be engrained into all industries that use or develop autonomous robotic technology. Entities are encouraged to follow a robust product development process based on a system engineering approach to minimize risks to safety, including those due to cybersecurity threats and vulnerabilities.

"Element 8: Crashworthiness," "94 breaks down into two sub-elemental categories. One being occupant protection and the second being compatibility. Occupant protection encourages entities to "consider incorporating information from the advanced sensing technologies needed for ADS operation into new occupant protection systems that provide enhanced protection to occupants of all ages and sizes." ${ }^{95}$ While compatibility encourages and/or suggests that "ADSs intended for product or service delivery or other unoccupied use scenarios should consider appropriate vehicle crash compatibility given the potential for interactions with vulnerable road users and other vehicle types." 96

"Element 9: Post-Crash ADS Behavior," ${ }^{, 97}$ NHSTA encourages entities to both to engage in "testing or deployment should consider methods of returning ADSs to a safe state immediately after being involved in a crash" and develop "communications with an operations center, collision notification center, or vehicle communications technology exist, relevant data is encouraged to be communicated and shared to help reduce the harm resulting from the crash." ${ }^{.98}$

91. Id.

92. Id.

93. Id. at 11 .

94. Id. at 12 .

95. Id.

96. Id.

97. Id. at 13 .

98. Id. 
"Element 10: Data Recording," for future development of all autonomous robotics usage. The NHSTA encourages entities to learn from crash data in order to develop safer methods, by gathering data from "on-road testing and use, and entities are encouraged to adopt voluntary guidance, best practices, design principles, and standards issued by accredited standards developing organizations such as SAE International."

"Element 11: Consumer Education and Training,"101 NHTSA stresses that it is imperative for increased safety during the development process and the usage of ADS robotic systems. Therefore:

entities are encouraged to develop, document, and maintain all information and give to any employee, dealer, distributor, and consumer about all education and training programs to address the anticipated differences in the use and operation of ADS from those of the conventional vehicles that the public owns and operates today. ${ }^{102}$

Such programs, should be aimed to teach operators and distributors the proper manners and/or standards to maintain, in order to avoid any possible legal ramification from either parties or patents during later usage. ${ }^{103}$

"Element 12: Federal, State, and Local Laws,"104 as mentioned below, state laws and federal laws have different ways of defining, interrupting, and handling issues of legal problems associated with ADS robotic systems. As such:

entities are also encouraged to document how they intend to account for all applicable Federal, State, and local laws in the design of their vehicles and ADSs. Based on the operational design domain(s), the development of ADSs should account for all governing traffic laws when operating in an automated mode for the region of operation. ${ }^{105}$

In 2016, the Society of Auto Engineers International published guidelines and a chart for autonomous vehicle classification known as SAE J3016. ${ }^{106}$ The SAE J3016 guidelines allow for easier classification of autonomous vehicles into six different levels of autonomous ability. ${ }^{107}$ Through formal acknowledgment, the central focus of the SAE J3016 is to create "a clearer and in some ways simpler framework for an ongoing conversation between industry stakeholders,

99. Id. at 14 .

100. Id.

101. Id. at 15 .

102. Id.

103. See id.

104. Id. at 15

105. Id.

106. Jennifer Shuttleworth, SAE Standards News: J3016 automated-driving graphic update, SAE INT'L: SAE J3016: LeVEl of Driving Automation (Jan. 7, 2019), https://www.sae. org/news/2019/01/sae-updates-j3016-automated-driving-graphic [https://perma.cc/ZNV4-EU62].

107. See id. 
advocates, and state and local governments that can help direct ongoing regulatory efforts as the industry continues to progress." ${ }^{108}$ The SAE J3016 breaks down each level by how autonomous the vehicle is. ${ }^{109}$ Additionally, the higher the level one's vehicle is classified as, the more regulation, tests, controls, and protective features the vehicle must maintain and possess. ${ }^{110}$

Level Zero: No Automation, contains "[t] he full-time performance by the human driver of all aspects of the dynamic driving task, even when enhanced by warning or intervention systems," and is fully operated by a human driver. ${ }^{111}$ Typically, a level zero is your everyday car with just enhanced features such as review cameras, side mirrors cameras and etc. ${ }^{12}$

Level One: Driver Assistance, ${ }^{113}$ contains "the driving mode-specific execution by a driver assistance system of either steering or acceleration/deceleration and using information about the driving environment and with the expectation that the human driver perform all remaining aspects of the dynamic driving task." 114 Level one classified vehicles are operated predominantly by human drivers, but as stated above, maintain features are governed my autonomous robotics. ${ }^{115}$

Level Two: Partial Automation, ${ }^{116}$ contains the same features as level one classified vehicles, but shifts further towards complete automation, and containing more features of robotic function. ${ }^{117}$

A modern-day example of level one and two classified vehicles would be the 2014 Jeep Cherokee, which maintains a self-parking robotics system. ${ }^{118}$ The selfparking features are just an individual autonomous feature that allows the robotics system to park while maintaining the rest of the vehicle operational by a human driver. ${ }^{119}$ Members of the Society of Auto Engineers International made a clear

108. U.S. DOT Chooses SAE J3016 for Vehicle-Autonomy Policy Guidance, SoC'y OF AuTO. ENGINEERS INT'L (Sept . 20, 2016, 5:39 AM), http://articles.sae.org/15021/ [https://perma.cc/SL8DHZYQ] (quoting Statement from Jeremy Carlson, Principal Automotive Analyst, IHS Markit).

109. See id.

110. Id.

111. Soc'y of Auto. Engineers Int'L, Automated Driving: Levels of Driving Automation are Defined in New SAE International Standard J3016, https://templatelab. com/automated-driving/ [https://perma.cc/3TX4-6G7F].

112. $I d$.

113. Id.

114. Id.

115. Id.

116. $I d$.

117. Id.

118. Jonathan Elfalan, 2014 Jeep Cherokee Limited Long-Term Road Test, EDMUNDS (Mar. 2, 2020), https://www.edmunds.com/jeep/cherokee/2014/long-term-road-test/2014-jeep-cherokeelimited-park-like-a-jerk-assist.html [https://perma.cc/9GZD-2NDJ].

119. Ed Grabianowski, How Self-parking Cars Work, HowStuffWorks, https://auto. howstuffworks.com/car-driving-safety/safety-regulatory-devices/self-parking-car.htm [https://perma.cc/QCA9-NYCJ]. 
break between levels $0,1,2$ and 3,4,5. This is reflected in the clear language division, separating non-autonomous vehicles from autonomous. ${ }^{120}$ This separation created and will continue to create different types of regulations, procedures, and tests that will need to be met and passed in order to be allowed to hit the streets of today's world. The next tier of classification maintains the same overarching regulations and status of containing " $[t]$ he driving modespecific performance by an automated driving system of all aspects of the dynamic driving task." 121

Level Three: Conditional Automation, ${ }^{122}$ is an automatize vehicle "with the expectation that the human driver will respond appropriately to a request to intervene." 123

Level Four: High Automation, ${ }^{124}$ contains that robotic system features that will intervene even if the human driver does not appropriately request said intervention when the vehicles believe that intervention is appropriate. ${ }^{125}$

Level Five: Full Automation, ${ }^{126}$ lastly contains that robotic system features that control every aspect of the vehicle "under all roadway and environmental conditions that can be managed by a human driver." 27

Both the Society of Auto Engineers International's guidelines to help regulate and charts determining levels of automation are key aspects of regulating autonomous vehicles that could be easily translated and or used when creating regulations for fully autonomous surgical robotics. ${ }^{128}$ Not only could some language be used in both, the overall structure of breaking down autonomous surgical robotics into different levels of automation and creating elemental standards as the U.S. Department of Transportation and National Highway Traffic Safety Administration did, it would also be beneficial to autonomous surgical robotics. ${ }^{129}$ Both aspects of structure and language usage will be addressed in more depth later in the note. However, its key to note that it is imperative for lawmakers to thoroughly look through past bills and guidelines as the ones examined above in order to determine what aspects and notions would and would not work when creating future bills of standards and regulations for fully autonomous robotics in the near future.

120. See Soc. OF AUto. EngineERs InT'L, supra note 111.

121. See Yamauchi Mia, Why We Need a Meaningful Comparison of Vehicle Autonomy, PLUGLESS, https://www.pluglesspower.com/learn/need-meaningful-comparison-vehicle-autonomy/ [https://perma.cc/BA4N-EG4G].

122. See Soc. Of Auto. Engineers Int'L, supra note 111.

123. Id.

124. Id.

125. See id.

126. Id.

127. Id.

128. Id.

129. Id. 


\section{State Statutes and Regulation}

As seen above, the purpose of the national standards is to help classify more readily how autonomous a vehicle is and how much regulation it should receive. ${ }^{130}$ Unlike the nationwide standards, each state bill is a more thorough breakdown of each component of what it means to be a full, partial, or semiautonomous operated vehicle. ${ }^{131}$ This notion of a thorough breakdown is reflexed by language seen within the bills of Michigan and Colorado. Each bill contains specific aspects that will help lay down a key foundation in order to create a potential solution that would help regulate the futuristic problem of fully autonomous surgical robotics. ${ }^{132}$

In 2013, Michigan passed legislation that focused in on how to control and determine damages, specifically product liability damages, that are caused by autonomous driving vehicles. ${ }^{13}$ The main driving force behind the bill is to allow technology to grow at a rapid rate in order to keep up with social needs. ${ }^{134}$ However, the legislation is not without any regulations. It requires all autonomous vehicles to adhere to all safety requirements related to autonomous vehicle testing. ${ }^{135}$

In 2017, Colorado passed a bill that focused mainly on test procedures and regulations on autonomous vehicles before they are even allowed to be used in society. The overarching concept of the bill is that any automated driving system vehicles that are not yet capable of complying with all state and federal laws cannot be tested unless approved by the Colorado State Patrol in the Department of Public Safety (DPS) and the Colorado Department of Transportation (CDOT). ${ }^{136}$ What makes the Colorado bill different from other regulatory bills is the language pertaining to the dual regulation of complying with all state and federal laws. This reflects a harsh standard on all autonomous vehicles and ensures greater levels of safety. This concept of dual complication is a concept that the legal field should consider and apply when creating bills and regulations

130. See Pratt Stephanie \& Boafo Kwame, Semi-Autonomous Motor Vehicles: What Are the Implications for Work-related Road Safety, CTS. FOR DisEASE CONTROL AND PREVENTION: NIOSH SCI. BLOG, (April 22, 2014) https://blogs.cdc.gov/niosh-science-blog/2014/04/22/semi-autonomousvehicles/ [https://perma.cc/7STA-ZM5A].

131. See Roy Alex, The Language of Self-Driving Cars Is Dangerous- Here's How to Fix it, THE DRIVE (May 9, 2018), https://www.thedrive.com/tech/20553/the-language-of-self-drivingcars-is-dangerous-heres-how-to-fix-it [https://perma.cc/DLP2-4ZL3].

132. Jack Karsten, Darrell West \& Christian R. Lansang, The state of self-driving car laws across the U.S., BROOKINGS: TECHTANK, https://www.brookings.edu/blog/techtank/2018/05/01/ the-state-of-self-driving-car-laws-across-the-u-s/ [https://perma.cc/V399-DJK3].

133. 2013 Mich. Pub. Acts 231.

134. 2013 Mich. Pub. Acts 231.

135. Autonomous Vehicles: Self-Driving Vehicles Enacted Legislation, NAT'L Conf. STATE LEGIS. (Oct. 2018), http://www.ncsl.org/research/transportation/autonomous-vehicles-self-drivingvehicles-enacted-legislation.aspx [https://perma.cc/59C3-HE39].

136. 2017 Colo. Sess. Laws SB17-213. 
centered around autonomous robotics. In addition to creating standards and regulations, the Colorado bill also addresses the concept of workload and revenue. The Colorado bill states that the application and use of automatic robotic systems will result in the potential reduction of traffic infractions by human error. ${ }^{137}$ By clearly stating the required measures to ensure these vehicles meet all legal and safety standards allows the court system to readily assert fines and other proper punishments when said standards are not. ${ }^{138}$ Lastly, the bill states that it is imperative that all local and state agencies apply this standard in a universal manner so that there is no confusion on what the standards and regulations are when the usage of autonomous vehicles occur. ${ }^{139}$

Both Michigan's 2013 Mich. Pub. Acts 231 and Colorado's G.A. Res., SB17213 contain key aspects and differences with their standards and regulations on how to control the notion of automation within the realm of self-driving cars. As time continues to move forward, it will be very important to continue to look at state laws and determine, from an objective standard, which aspects of their own laws are working, and which are not. In order to get the best and most useful nationwide regulatory bill for self-driving, but more importantly fully autonomous surgical robotics, it imperative to keep track and note what aspects of each state bill work and which aspects do not work. If lawmakers continue to watch this with a careful eye, there should be no reason not to have a key, uniform and functional bill in place in order to handle most issues that could arise out of usage and failures that occur with the application of fully autonomous surgical robotics within our given society.

\section{B. Aviation Statues and Regulations}

Similar to the automotive industry, the formulation of relevant statutes and regulations that are used to maintain proper usage of robotic systems occurred within the aviation industry. ${ }^{140}$ Specifically, the most popular usage of autonomous robotics in the realm of aviation is associated with the concepts of automatic landing and takeoff. ${ }^{141}$ The usage of automatic landing and takeoffs can be directly correlated to efforts of minimizing "the risks and increas[ing] repeatability of a flight at the same time as reducing the dependence on a human pilot; as the capabilities of the autopilot are improved the need for a skilled pilot is reduced." ${ }^{142}$ Even though the usage of auto land and takeoff helps reduce error and dependence, lawmakers have placed regulations on how often one can use it.

137. Id.

138. See id.

139. Id.

140. Magnus Vestergren, Automatic Takeoff and Landing of Unmanned Fixed Wing AirCRAFts: A SyStems EngINEERING APPROACH 1 (2016) https://liu.diva-portal.org/smash/get/ diva2:1055556/FULLTEXT01.pdf [https://perma.cc/WA6K-FK8H].

141. Id.

142. $I d$. 
The most vided example is statute 14 CFR $\$ 61.57$. The CFR statue is a federal statute that all commercial air pilots must follow and abide by ${ }^{143}$ CFR $14 \S 61.57$ states and/or implies that a pilot in command is required to at least perform three manual and takeoffs and three lands within 90 days. ${ }^{144}$ The importance of a statute like 14 CFR $\$ 61.57$ is the need for a "human safe net" when and/or if robotics system failure occurs. ${ }^{145}$ The safeguard of human ability/function of pilots to perform without the assistance of robotic systems helps to maintain the highestlevel safety possible. The key significance that can be used from the statutes and regulations above, is requiring doctors to perform a specific amount of surgeries without completely being dependent on the fully or semi-autonomous robotics. The rationale behind such a requirement would be in case of those "worst case situations" happening. Worst case being, where the autonomous surgical robotics cannot be used, due to power outage or any other reason, and the doctor would be able to perform the required surgery.

Overall, by examining the statutes and regulations around the usage of the autonomous technology within the automotive and aviation industries, similar language and policies can and should be used to formulate regulatory standards for the future development of fully autonomous robotics. ${ }^{146}$ Using statutes and regulations from one industry in another has historically been done and has shown strong and positive results in many different fields of law. ${ }^{147}$ Meaning, there is importance behind studying and analyzing past bills and statutes in order to learn what works and what does not work when creating future bills and regulations. This way the same mistake does not occur twice, and great policies can be built upon in order to create a stronger formulated bill for future legal disputes and issues.

\section{CASE LAW}

Just as important as statutes, both state and federal court case law is another key determinate on how society has already handled past issues involving surgical semi-autonomous robotics and how our court system should continue to use past precedent in the future. As Janet Fleetwood concluded for her study, the

143. 14 CFR $\S 61.57$ (2018).

144. Id.

145. See Jason Knight, Flying Artificial Intelligence Unmanned Aerials Systems IN THE UNITED STATES (2014), https://www.researchgate.net/publication/312042845_FLYING ARTIFICIAL_INTELLIGENCE_UNMANNED_AERIALS_SYSTEMS_IN_THE_UNITED_S TATES [https://perma.cc/JHP7-HXPR].

146. See Chris Middleton, US scraps driverless car regulations, redefines concept of 'driver', INTERNET BUS.: ANALYSIS (Oct. 5, 2018), https://internetofbusiness.com/us-scraps-driverless-carregulations-redefines-concept-of-driver/ [https://perma.cc/QK5Q-34MU].

147. See Tali L. Katz, Retrospective v. Prospective Amendments: When Does New Federal Legislation Impact My Case?, A.B.A. (Mar. 28, 2018), https://www.americanbar.org/groups/ litigation/committees/products-liability/practice/2018/retrospective-vs-prospective-amendmentswhen-does-new-federal-legislation-impact-my-case/ [https://perma.cc/Y4SQ-2GLW]. 
usage of autonomous robotics with the automotive industry has the potential to save nearly 29,000 lives per year in the United States. ${ }^{148}$ However, there are still issues and problems involving the usage of autonomous vehicles. One of the most common issues that courts have struggled to determine is who should be sued when the robotic system fails. As Ian Bogost examined in his article, is there even a legal possibility to sue a robot if a failure occurred and if not, who should be held liable? ${ }^{149}$ Just as we see this issue of who to sue with autonomous vehicle failures, the same issue remains true within autonomous surgical robotics. ${ }^{150}$ When such system failure occurs, injured parties look for responsibility to be taken, compensation to be given and justice to be served. ${ }^{151}$ Thus, the bigger question of how to handle what party should take responsibility for such failures occur within autonomous surgical robotics: the hospital, the surgeon, the manufacturer, or someone more individually associated with the development of the surgical robotic system. ${ }^{152}$ The issue of surgical robotic failures is an issue that is impacted by numerous fields of law, such as, medical malpractice, manufacture defect, design defect, and project liability. ${ }^{153}$ Each area of law stated above contains specific factors that make each one complex in their individualized way.

A clear example of how the court system has historically handled issues of surgical robotic failures is in Mracek v. Bryn Mawr Hosp., 363 Fed. Appx. 925 (3d Cir. 2010). ${ }^{154}$ In sum, a patient sued following a surgery that resulted in alleged damages stemming from the usage of a semi-autonomous surgical robot. ${ }^{155}$ The doctors performed the surgery on a man with the hospital's "da Vinci robot" which malfunctioned and performed an improper surgery. ${ }^{156}$ The plaintiff additionally also sued the manufacturer for providing a malfunctioning device that could not perform the surgery with the precision he needed. ${ }^{157}$ The issue and matter of concern was whether the manufacturer's liability after

148. Janet Fleetwood, Public Health, Ethics, and Autonomous Vehicles, 107 AM. J. Public HeALTH 532-37 (2017).

149. See Ian Bogost, Can You Sue a Robocar?, The Atlantic (Mar. 20, 2018), https://www. theatlantic.com/technology/archive/2018/03/can-you-sue-a-robocar/556007/ [https://perma.cc/B4DX-FLDX].

150. See David S. Kemp, Autonomous Cars and Surgical Robots: A Discussion on Ethical and Legal Responsibility, VERDICT (Nov. 19, 2012), https:/verdict.justia.com/2012/11/19/autonomouscars-and-surgical-robots [https://perma.cc/K5YS-EECG].

151. See David H. Sohn, Negligence, genuine error, and litigation, 6 INT. J. GEN. MED. 49-56 (2013).

152. See id.

153. Taelonnda Sewell, Robotic Surgery Lawsuits, Legal Match (2018), https://www. legalmatch.com/law-library/article/robotic-surgery-lawsuits.html, [https://perma.cc/HG3B-B22R].

154. Mracek v. Bryn Mawr Hosp., 363 Fed. Appx. 925 (3d Cir. 2010) (order granting summary judgment).

155. Id.

156. Id.

157. Id. 
voluntary dismissal of the hospital. ${ }^{158}$ The court focused on the notion/legal concept of secondary cause. ${ }^{159}$ Conclusively, the court held that patient presented no evidence to show that erectile dysfunction and groin pain were caused by robot malfunction ${ }^{160}$ and focused the rule of law that a patient bringing claims must additionally provide evidence that it was, in fact, the robot that caused the pain, injury, or serve discomfort. ${ }^{161}$ The major take away and rule of law from a case as such signifies that bad surgical outcomes can occur due to not using the readily available surgical robotics to perform the surgery. This demonstrates that the usage of surgical robotics can in fact reduce surgical mishaps and errors. ${ }^{162}$ As robots become better at precision or dangerous work than humans, we are likely to see more cases in which plaintiffs blame humans for not using robots. ${ }^{163}$ Additionally, the concept of strict liability has come into play for plaintiffs attempting to receive compensation and justice from alleged robotic failures. Meaning, that a plaintiff asserting a strict liability claim against a robot manufacturer must plead and prove, under a typical state's law, that the defendant sold a product that was defective and unreasonably dangerous at the time it left the defendant's hands, the product reached the plaintiff without substantial change, and the defect was the proximate cause of plaintiff's injuries. ${ }^{164}$

Additionally, the Washington Supreme Court laid down key foundational law for the realm of autonomous surgical robotics. ${ }^{165}$ The Washington court system focused on the notion of what should happen in the specific aspects of product liability and tort defense. ${ }^{166}$ In Taylor v. Intuitive Surgical, Inc, the Court noted that Washington's product liability law requires both the manufacture and hospital to be aware of and express the dangers of operations conducted by surgical robotics. It is the legal reasonability of the manufacturer to inform the hospital of any defects in the product, however, the hospital has an independent duty of care to their patients. ${ }^{167}$ Here, the Taylor case creates a clear chain of responsibility. It should be noted that even though states maintain the right to develop their own state law, it is not uncommon for other states to use different state precedent to, at least at a minimum, influence and potentially guide similar disputes that arise within their own legal system. Furthermore, in terms of tort

158. Stephen S. Wu, Summary of Selected Robotics Liability Cases 3 (2010), http://ftp.documation.com/references/ABA10a/PDfs/2_5.pdf [https://perma.cc/Y3GD-NYSZ].

159. Mracek v. Bryn Mawr Hosp., No. 09-2042, 2010 U.S. App. LEXIS 2015 (3d Cir. Jan. 28, 2010).

160. See id.

161. See id.

162. See Tara Kirkpatrick \& Chad LaGrange, Robotic Surgery: Risks vs. Rewards, PATIENT SAFETY NETWORK (2016), https://psnet.ahrq.gov/webmm/case/368/Robotic-Surgery-Risks-vsRewards- [https://perma.cc/6NWR-858A].

163. Wu, supra note 158.

164. See id.

165. Taylor v. Intuitive Surgical, Inc., 187 Wash. 2d 743 (2017).

166. Id.

167. Id. 
defense, the Washington Supreme Court accepted the defense of Comparative Fault, to apply in the situation of robotic failure in surgeries. ${ }^{168}$ The major take away from Washington's case law is the creation of key protections for the hospitals when robotic failures occur. This foundation law spreads the notion of liability between all parties involved. i.e. the patient who got hurt, the hospital and doctor who performed the surgery and the manufacturer who created the robotic device.

Overall, legal disputes involving robotic failure will continue to occur in the realms of medicine, automotive, and aviation. As such, it is important to keep and note major holdings that are handed down, not only by the federal court systems but the state level as well. Due to the rapid rate of advancement of robotics and the impact robotic failure maintains upon the legal system as a whole, it is vitally important for legal scholars and makers to keep up to date with all advancements. ${ }^{169}$ Thus, both federal and state legal systems will be analyzing and using other precedents in order to handle any future disputes or litigation that will occur in the future while continuing to rely on experts in the field of robotics. ${ }^{170}$

\section{RECOMMENDATION FOR COURSE OF ACTION}

It is gradually becoming more conceivable that complete autonomous robotics, specifically surgical ones, will change not only the world of medicine but also the world of law and the profession of lawyers in the near future. As such, both legal and statutory provisions should be discussed and developed at the same rate as surgical technology progresses. As examined above, both our legal and law-making bodies have already begun to address the overall concept of autonomous robotics that already exists. By using preexisting statutory and case law, the remainder of this note will address and highlight a possible legal/statutory foundation to handle the futuristic notion of complete autonomous surgical robotics.

The principal piece of insight and/or guidance that will be addressed is the United States Department of Transportation \& National Highway Traffic Safety Administration Twelve Elements of Autonomous Robotic Vehicles, with the addition of both federal and state statutory and case law. While, maintaining the twelve structural components, the possible course of action will be to adjust historic statutory and case law to focus on surgical robotics rather than vehicles; this should provide a clear foundation for further and future statutes and case law precedent. The notion of universal standards is one more major importance. Meaning that with the application and implementation of universal standards, it reduces companies' and hospitals' ability to get out of lawsuits by finding

168. Id.

169. See Hallie Siegel, American law needs a reboot when it comes to robots, MEDIUM (Mar. 5, 2016), https://medium.com/silicon-valley-robotics/american-law-needs-a-reboot-when-it-comesto-robots-7582dc1224c1 [https://perma.cc/U3NL-XVKE].

170. See id. 
loopholes within their given state's regulations and standards. Additionally, as we have seen through the history of our court system, applying historic precedent makes handling all later suits simpler in nature, as each case will be applying the same rules and regulations.

\section{A. Basic Classification}

In a similar manner as the SAE J3016 document lays out a six-tier classification system used to readily determine how autonomous a self-driving vehicle is, the same should be done for automated surgical robotics. ${ }^{171}$ Creating and developing a similar classification system for the level of autonomy for surgical robotics should be the first step in developing a possible course of action to handle the legal and statutory problems that may/will occur with usage. As examined above, each tier level of the SAE J3016 is determined by how autonomous the robotics system is. ${ }^{172}$ Level 0 equaling completely human operational, to level 5 equaling completely autonomous. ${ }^{173}$ Each level would determine how much regulation and testing the autonomous robotics system should and will need to receive, in order for it be allowed for use in today's society.

In a similar fashion, the SAE J3016 version for surgical robotics should follow in the same manner. A level zero classification would consist of only human operation with non-surgical robotic assists. In a modern world of medicine, this would be your regular check-up in the doctor's office. A level one and two classification would consist of dominantly human operation with minor or partial usage of surgical robotics. An example of a level one and two classification would be the usage of small high-quality cameras that are used during laparoscopy surgery. The rationale behind such a classification is that the doctor uses instruments controlled by their hands and guided by the camera. ${ }^{174}$ Here, though robotic systems are used, they are in full control by the doctor or surgeon. Through analogy, this would be the same as a vehicle's review or side camera system. Level three and four would consist of the surgical robotics that is in use today, such as the "da Vinci, Sensei X Robotic, CorPath 200, Vdrive robotic." ${ }^{\prime 75}$ As explained earlier in the note, these surgical robots are not completely autonomous, but rather they are classified as semi or partially autonomous. Lastly, the level five classification is left for the futuristic development of complete autonomous robotics. Though fully autonomous robotics currently do not exist in today's medical realm, creating a possible

171. U.S. DoT Chooses SAE J3016 for Vehicle-Autonomy Policy Guidance, SAE InT'L (Sept. 20, 2016), http://articles.sae.org/15021/ [https://perma.cc/SL8D-HZYQ].

172. Id.

173. Id.

174. Cameras Becoming Instrumental in Successful Surgeries, AIA Vision Online (Jan. 12, 2016), https://www.visiononline.org/blog-article.cfm/Cameras-Becoming-Instrumental-inSuccessful-Surgeries/3 [https://perma.cc/7ETS-NDLK].

175. Densford, supra note 49. 
statutory structure on how to regulate and or handle legal disputes would not only allow for a swift transition, it would additionally stimulate development and future usage. Even though this only a basic classification system with little or no qualification determinates, below will analyze and discuss what features and functions will help determine how autonomous a robotics system should be classified as and determine what regulation should be applied.

\section{B. Foundational Element Requirements}

Elements one through three will focus on System Safety, Operational Design Domain, and Object and Event Detection and Response. ${ }^{176}$ Thus, by applying similar language and foundational concepts used to determine the level of autonomy in a vehicle, one should be able to transition and transform said language and conceptual notions in order to readily classify and determine the level of autonomy in surgical robotics. This note will only be addressing elements one, two, and three as they are the key foundational elements in order to obtain the result of creating a regulatory bill for the future usage of fully autonomous robotics.

\section{Element One}

System Safety: is an element that emphasizes regulations upon autonomous surgical robotics. In sum, any entities that are manufacturing, developing, and or creating fully autonomous surgical robotics need to follow and adopt the best practices, design principles, standards, and processes available from other industries such as aviation, space, military, and the automotive industries. ${ }^{177} \mathrm{By}$ requiring such adoptions of other industries' standards, we as a legal community can help promote that any surgical robotics system that will be used is as free from unreasonable safety risks as possible. Ensuring that the risk for failure and or malfunction is minimal is a cornerstone that all industries should strive for. The legal consequences for not meeting the requirements of element one would be either the product not being approved by the Food and Drug Administration and/or a heavy fine.

\section{Element Two}

Operational Design Domain: in the realm of autonomous vehicles, this elemental lays down basic requirements that all autonomous vehicles should maintain before being approved for society usage. Instead of requiring surgical robotics to maintain capabilities such as road type classification and speed range, we should require the classification of environmental conditions in which

176. U.S. Dep't of Transp. \& Nat'L Highway Traffic Safety Admin., supra note 65.

177. Id. 
operation can occur. ${ }^{178}$ Element two for surgical robotics would consist of types of surgical usage. Examples being: type of operation, success rate, quickness of operation, and error rate (compared to if the same operation was done by a human). These requirements would have been known by all parties involved in the operation, ie. doctor/surgeon, manufacture, operator, and the patient who is receiving the operation. The legal importance behind element two would focus on tort defense and liability. If parties all are informed about all aspects of the surgical robotics system, it would help reduce legal questions as what was seen and dealt with in the Washington Supreme Court case. ${ }^{179}$ Overall, requiring the industry of surgical robotics to meet the standards of element two would help clean up and make court cases involving completely autonomous surgical robotics failure easier and more readily determinable by judges and lawyers.

\section{Element Three}

Object and Event Detection and Response: would be an elemental requirement that would force entities to have clear and readily available documentation of assessment, testing, and validation of their autonomous robotic system's capabilities. ${ }^{180}$ Not only would this be important for legal consequences, but it would also be significant for the growth and development of surgical robotic systems. In terms of legal significance, requiring documentation would allow courts, judges, and lawyers to determine whether it was manufacturing error, process error, or operator error. Meaning, it will not by itself determine who is liable for the system failure, however, it will provide a better insight into what parties are allowed to be sued. Overall, requiring the following of element three would create an environment of efficiency, which would develop better law when having to handle issues surrounding surgical robotic system failure. ${ }^{181}$

As stated earlier, this problem of handling the future notion of fully autonomous robotics is one that is complex. As such, this potential solution is only foundational in nature. In the years to come, more research and knowledge is going to be obtained to develop a bill that can meet all concerns and problems associated with fully autonomous robotics. Overall, the legal community must develop something that is similar in nature to the possible solution stated above. This request is not one of personal concern, but rather can be reflected in the current legal issues already arising out of the semi-autonomous surgical robotics as mentioned above.

178. Id.

179. Taylor v. Intuitive Surgical, Inc., 187 Wn.2d 743, (Wash. 2017) (The main issue in the case was what party was most liable when a semi-autonomous robotic system failure occurred. Emphasized the notion of comparative negligence making all parties involved, including the patient to be considered liable).

180. U.S. Dep't of Transp. \& Nat'L Highway Traffic Safety Admin., supra note 65.

181. Id. 


\section{Legal and Ethical Significance}

The importance of determining the level of autonomy between the surgical robotics we have today and those in the future is reflected by both legal and ethical significance. As Thomas Claburn alluded to in his article, surgical robotics and self-driving cars have already started to create legal and ethical "headaches." 182 A legal and ethical headache on its face might come off as minor significance, however, that may not be the case. As stated earlier, historic practices, regulations, and policies have played vital roles in developing solutions for problems that occur at a later date. Policies adapt as time changes, case precedents are used for years, and regulations are shaped in order to combat changes and provide the best results. Thus, as Thomas Claburn alluded to in his article, examining the legal "headaches" that have occurred with semiautonomous surgical robotics and self-driving cars may create a possible solution for both legal and ethical problems associated to the development of fully autonomous robotics. ${ }^{183}$

As examined above, courts have struggled to determine what parties should be liable when surgical robotics failure occurs. ${ }^{184}$ Courts have typically taken the route that all parties involved in the manufacturing, usage, upkeep, and even in some cases, the patient are all liable in some sort of way. ${ }^{185}$ Thus, creating a legal precedent of being able to sue any parties that had any contact and/or part in the creation and usage of surgical robotics. As time moves forward and surgical technology rapidly advances, specific parties will be further extended from direct care to the development and usage of the robotics. ${ }^{186}$ Specifically, it would be extended to the surgeon or doctor who would be using said robotics during operational procedures. ${ }^{187}$ As such, it would be both legally and ethically unjust to allow parties to sue an individual who cannot be directly attached for being a cause for the robotics failure. Though this is just one hypothetical situation in which legal questions and concerns arise. It nevertheless demonstrates the significance in the determination of whether a robotics system is either partial or fully autonomous and the result of different legal ramifications for parties involved.

As briefly mentioned above, there is also ethical significance attached to the usage of advanced autonomous robotics. This ethical significance mainly falls, as Fanny Ficuciello and associates determined, around the sharing of

182. Claburn Thomas, Robo-surgeons, self-driving cars face similar legal, ethical headaches, THE REG. (July 13, 2017), https://www.theregister.co.uk/2017/07/13/robot_surgeons_face_same_ obstacles_as_selfdriving_cars/[https://perma.cc/N8RW-ZEUK].

183. See id.

184. Wu, supra note 158.

185. Id.

186. Thomas, supra note 182.

187. See id. 
responsibility between the doctor and robotics performing the surgery. ${ }^{188}$ Meaning, who or which party is morally liable in the situations where the robotics fail. ${ }^{189}$ This is not only a true ethical problem but also a legal one. The result for the legal problem may be justified in which party is at fault, however, the notion of an ethical/moral factor may generate a different solution. Is it ethically justified to always blame the doctor? This notion of ethical significance is something that lawmakers and practicing judges and lawyers must keep in the back of their minds when handing down judgments or passing statutes. The legal solution may be correct for the given situation, but the ethical issues involved must also be weighed into the formulation of the overall solution. As in most things relating to health care, medical practices, and surgeries, the concept of innocent individuals' lives being impacted is something that should be recognized. As society is rapidly developing towards fully autonomous surgical robotics, the notion of humanity must not be forgotten.

\section{CONCLUSION}

Though there is already foundational law and statutes governing the uses and standards of autonomous robotics, this does not solve the foreseeable problems in the near future. As autonomous robotics continue to develop and grow at rapid rates, the law and statutes governing them need to as well. If the law does not follow in suit, this could potentially create legal gaps in handling of future disputes. As this note highlights, one of these potential legal gaps can be seen within the notion of complete autonomous surgical robotics and its relation to medical malpractice and products liability. Though some critics may claim that the notion of complete autonomy is one of far fetch nature, it has been clearly proven throughout this note that is not true.

If no such solutions are developed in order to handle the regulations and the legal conflicts, we as a society run the risk of overloading not only our judicial system but our nation's policymaking body. As technology develops at an unprecedented rate, the need for an in-depth examination of the concepts, possibilities, problems, and possible legal solutions is needed in order to help handle and maintain all issues and regulations that will occur for the use of fully autonomous surgical robotics.

188. Ficuciello Fanny et. al., Autonomy in surgical robots and its meaningful human control, 10 Paladyn, J. Behav. Robotics 30 (2019).

189. See id. 